\title{
Design Inspiration Naturalism on Apparels
}

\author{
${ }^{1}$ V.S.Karpagavalli and ${ }^{2}$ Dr. M.Sumithra \\ ${ }^{1 \& 2}$ Assistant Professor \\ ${ }^{1}$ Dept. of B. Voc Garment Designing PSGR krishnammal College for Women, Coimbatore, \\ 2 Textiles and Apparel Design, Bharathiar University Coimbatore, Tamil Nadu, India.
}

\section{ABSTRACT:}

Nature is the main visual apparel design sources of inspiration have a creative function. Clothing design is examined in terms of its early phases of development, how design inspiration is acquired, and how it affects clothing design's creativity and uniqueness, among other things. Naturalism's objectivity is shown by its interest in human nature and its factual portrayal in scientific ways with the goal of discovering the genuine meaning of human existence in nature. To begin, we'll go through the terms "naturalism" and "natural clothing" in brief. Nature-friendly and high value modem designs may be created by grafting natural pictures onto human bodies, according to the paper's notions. To find out whether universal design can be used in the apparel industry, this research looked at the possibilities.

Key words: Naturalism, Theme selection, Inspiration, Nature Inspiration.

\section{INTRODUCTION:}

Nature is an excellent approach to re-energize one's spirit and relax one's thoughts. This provides a new way of looking at design. The most crucial component of drawing inspiration from nature is to pay attention to it and integrate the features into the design aspect. In fashion design, the textures, colours, and textures of leaves, grass, and water may be employed artistically. Nature has been a significant source of inspiration for artists for generations. In today's world, just celebrating nature isn't enough. Fashion designers' creativity, along with proper patterns and colour choices, results in outfits that are ageless and elegant, allowing clients to wonder at nature's beauty. Nature's inspiration for the fashion business is evidence certain that Mother Nature is the industry's biggest muse. [1]. 
Fashion is, by definition, an ever-changing art form. Oscar Wilde once said, "Fashion is a form of ugliness so intolerable that we have to alter it every six months" However, it is the fashion industry's perpetual growth, the continual re-invention of previous trends as well as the emergence of new ones that gives it its thrill and allure. A fashion show is an event put on by a fashion designer to showcase their innovative clothing. An innovative collection is produced by a designer, brand, company, group of people, etc. The fashion A fashion show's key aspect is a moving body parade, which spawned the modelling industry. Fashion shows represent every season such as the summer, spring, winter and autumn. The fashion show should have a theme, a central basic idea on which the show is built. The theme will say about the type of merchandise being shown and the audience from whom the show is prepared. A theme suggests signs, publicity and programme.

\section{Design Development Process:}

\subsection{Research Development:}

Research is the process of looking for and recording artistic information in a manner to build a library of visual information that can be used for inspiration. When you record research material, you have a place to start coming up with ideas. They can arrive from anywhere, and they can be totally unique and only linked to the designer in a really unique way. An investigative researcher looks for and records data from a wide range of sources, such as ancient sources, museums, exhibitions and shops, as well as collecting materials, taking pictures of construction techniques, and exploring a particular location in depth. This can be drawn or photoed from any source and includes a wide range of images, raw material, color schemes, articles, illustrations, cloths, scraps of paper, wallpaper, advertisements, photos, trimmings and articles, as well as anything that is aesthetic and contextually inspiring. Something physically and conceptually attractive may be included here. When doing research, it is important to demonstrate to potential employers that you are aware of the importance of this component of design. Work backwards through your fashion career history to learn about current fashion trends and colors. [2]. 


\section{2. Theme/Mood board Mood boards}

A collection of photos, textures, and colours, among other things, that have been assembled with the purpose of expressing a visual message that will elicit a certain emotion in the viewer to inspired designs. A mood board is a visual representation of the inspiration and concept for your collection. In the course of developing your line, it will serve as a design tool to keep you focused and consistent. Furthermore, it serves as an excellent communication tool for conveying your vision to others. Magazine shreds, fabric swatches, vintage photographs, buttons, ribbons, and pretty much any other visual reference you choose are posted on a hard board for easy access. Make sure to give your narrative board a title, such as the title of a book or a movie.

\subsection{Inspiration board:}
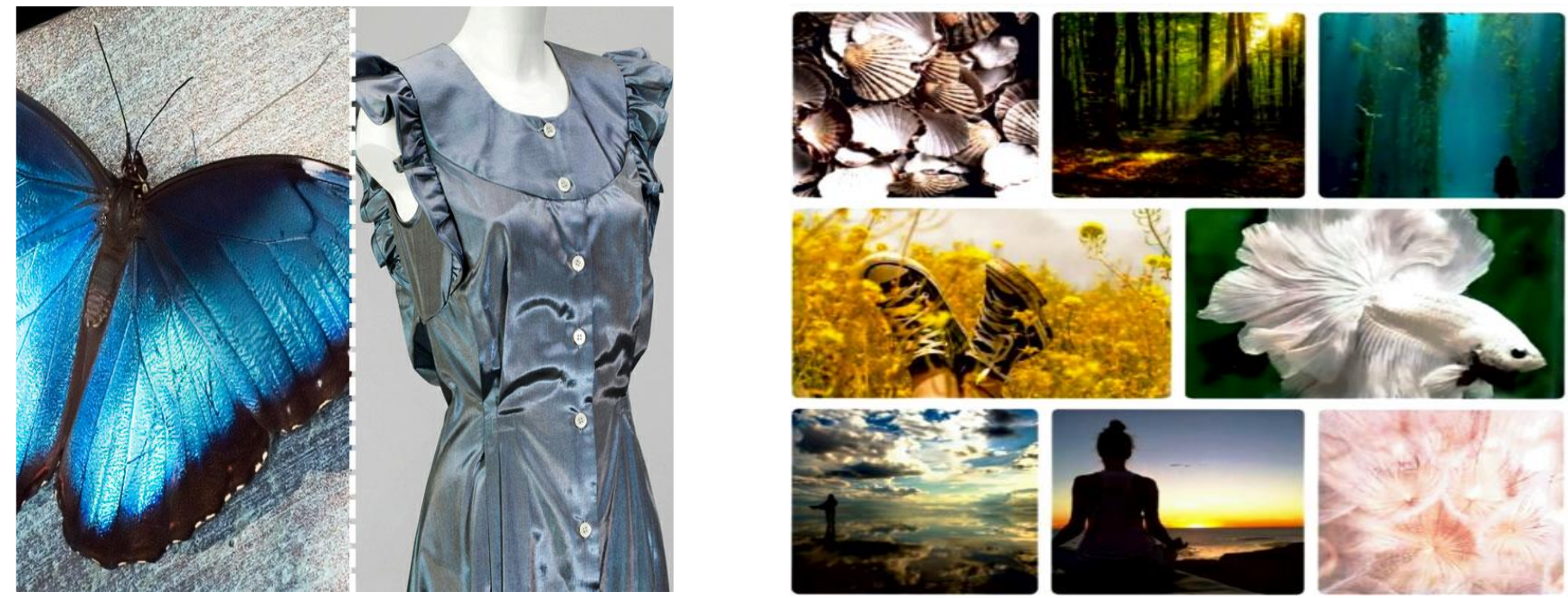

Fashion needs the "fresh" to be an inspiration for new designs and to provide customers with something fresh.

What motivates a new season is an essential part of the season itself. Color, print, pattern and texture are all ways to keep the fashion customer engaged in today's visual-heavy environment. Gathers all the visual cues for the finished result. Collection of visual cues that serve as the beginning point for components. The mood board should inspire the inspiration board. A visual representation of a concept Sketches may be shown individually. As a result, those of us who see your drawing process as a key component of your presentation will benefit from this. The positions shown in the illustrations are purposefully slanted in the direction of the topic. The style has a fresh, young, laid-back, but still practical and urban vibe to it. 


\subsection{Color board:}

Color stories are often expressed using whatever colour samples are available, such as flat fabrics, yarn samples, swatch samples, and so on, because colour is the first development of a new season. Color palettes are inspired by exhibitions, gallery visits, interest in particular cultures, unusual imagery, or historical imagery.
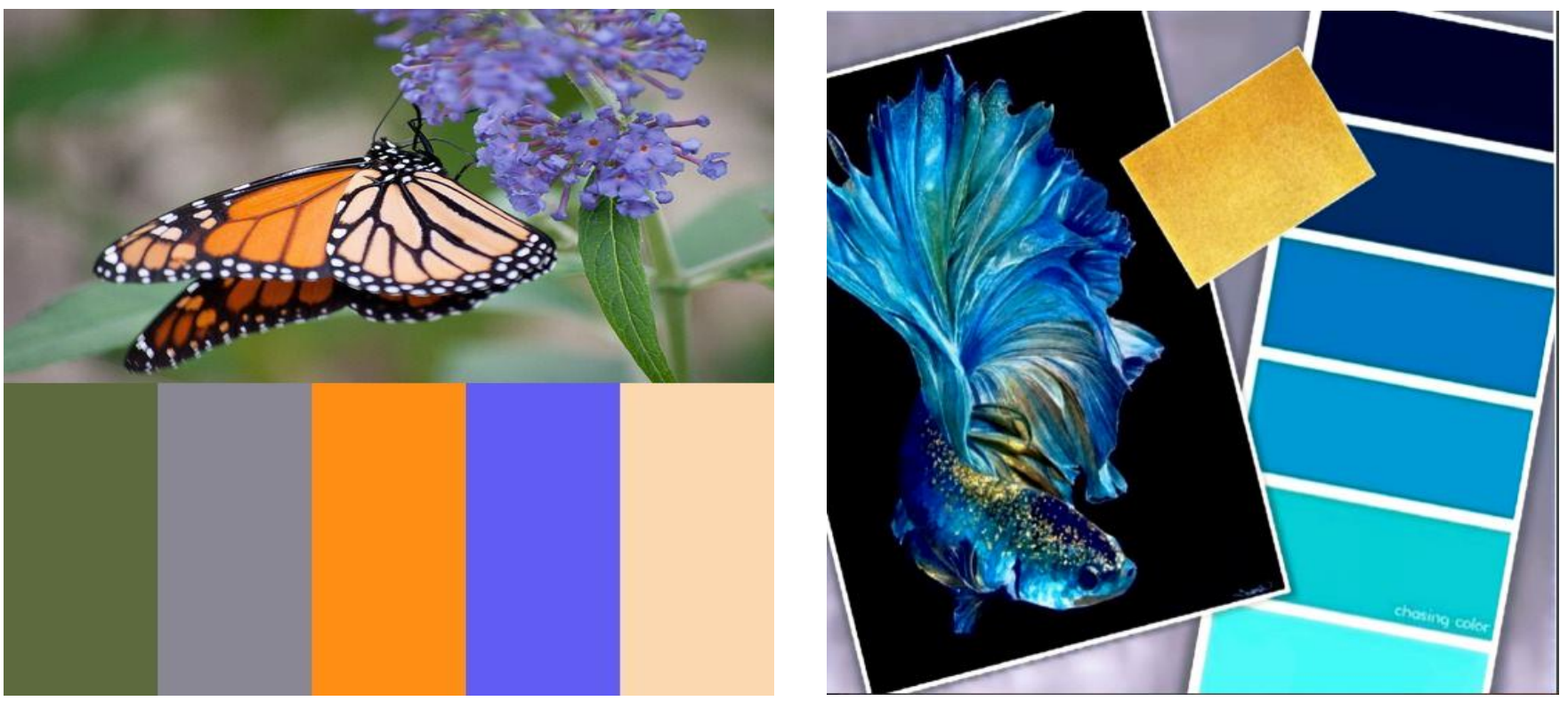

\subsection{Range Plan:}

The range plan is the conceptualization of the actual visual chart collection. This includes many sketches and ideas for different garments of the collection. The garments are sketched with details. It allows you to further imagine how the pieces will coordinate together and how each contributes to the whole look of the collection. These individual garments are then put together and draped onto croquis to create the final collection. Below are some examples of range plans of major international designers from previous seasons. Here, you can see that it's all about a mix and match of multiple items [3]. 

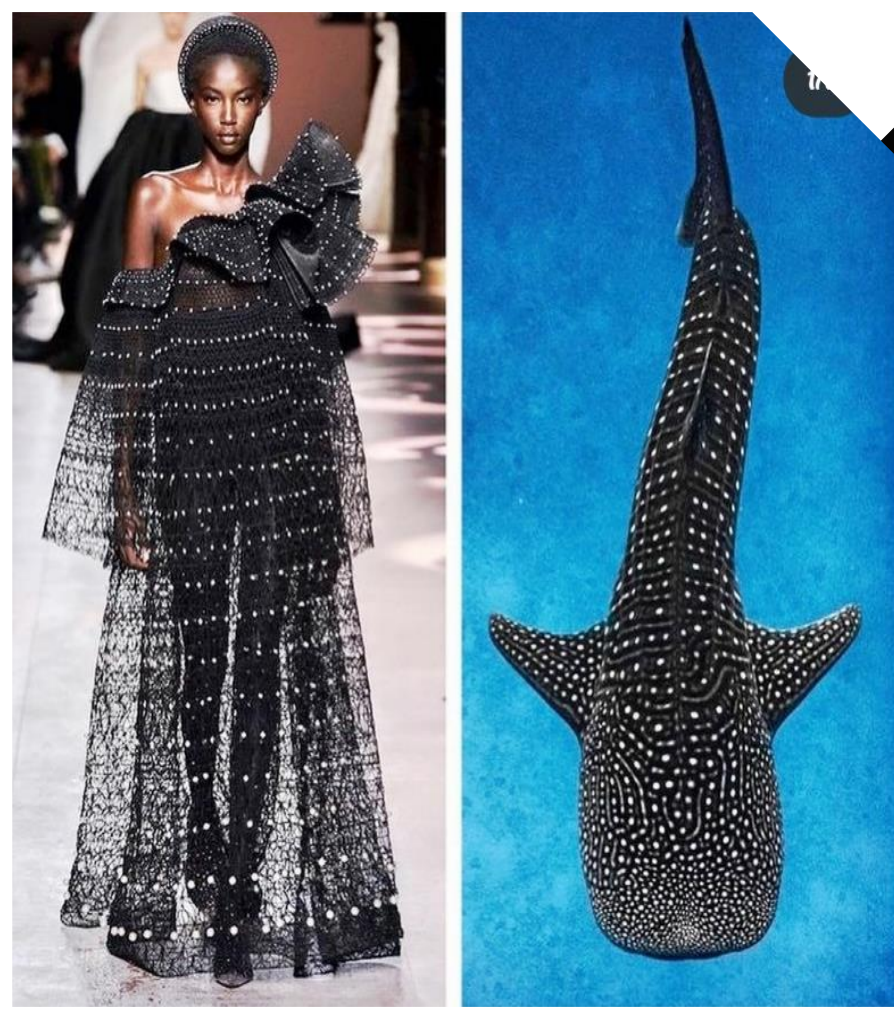

Fig no.1. Inpiration from Fish
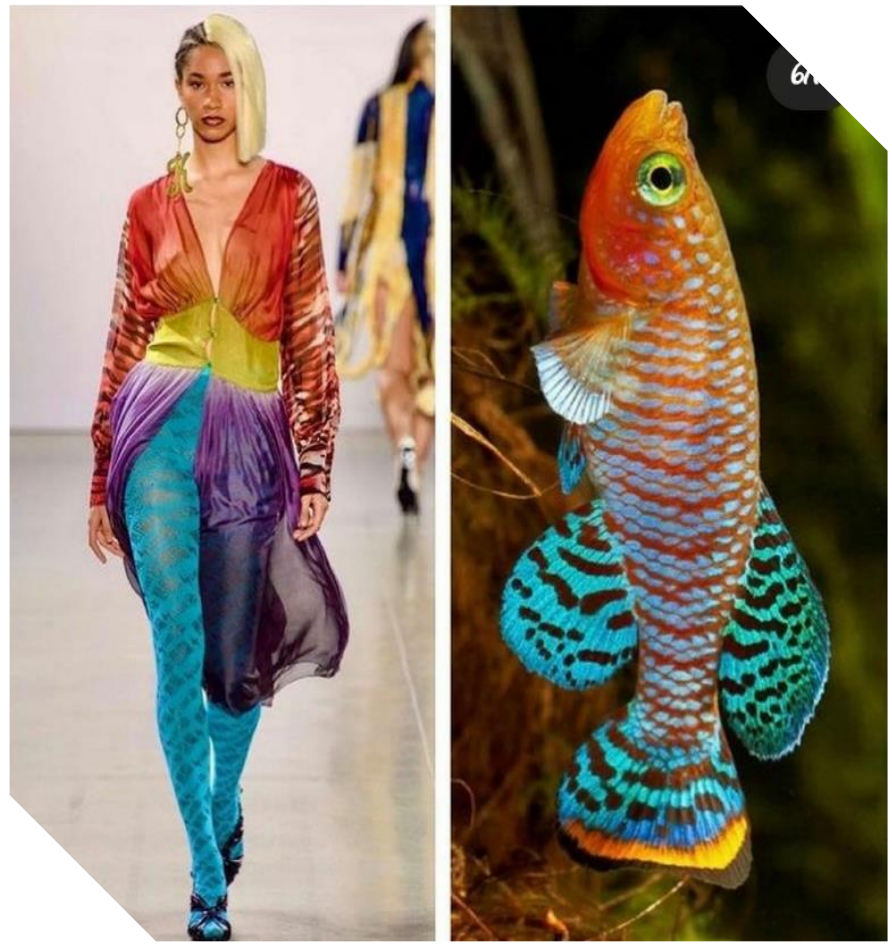

Fig no.2. Inpiration from Jelly Fish
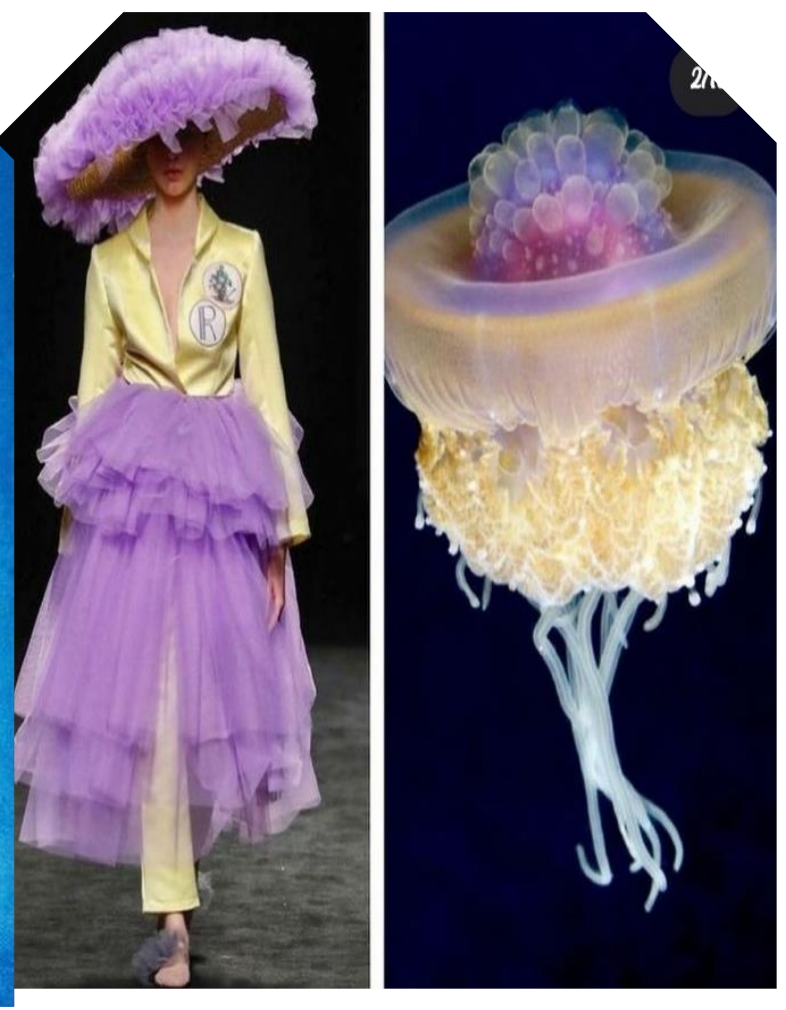
Fig no.3. Inpiration from Parrot Fish

Fig no.4. Inpiration from Butterfly

Fashion Designers \&B rands Inspired by Naturalism in current Trend:

\subsubsection{Rhopalocera - Designer Charles James}

The "Butterfly" dress by Charles James (1955) is possibly

one from his most noteworthy costumes since it exemplifies his extraordinary attention to the details and structural ability. James often used similar textiles in different
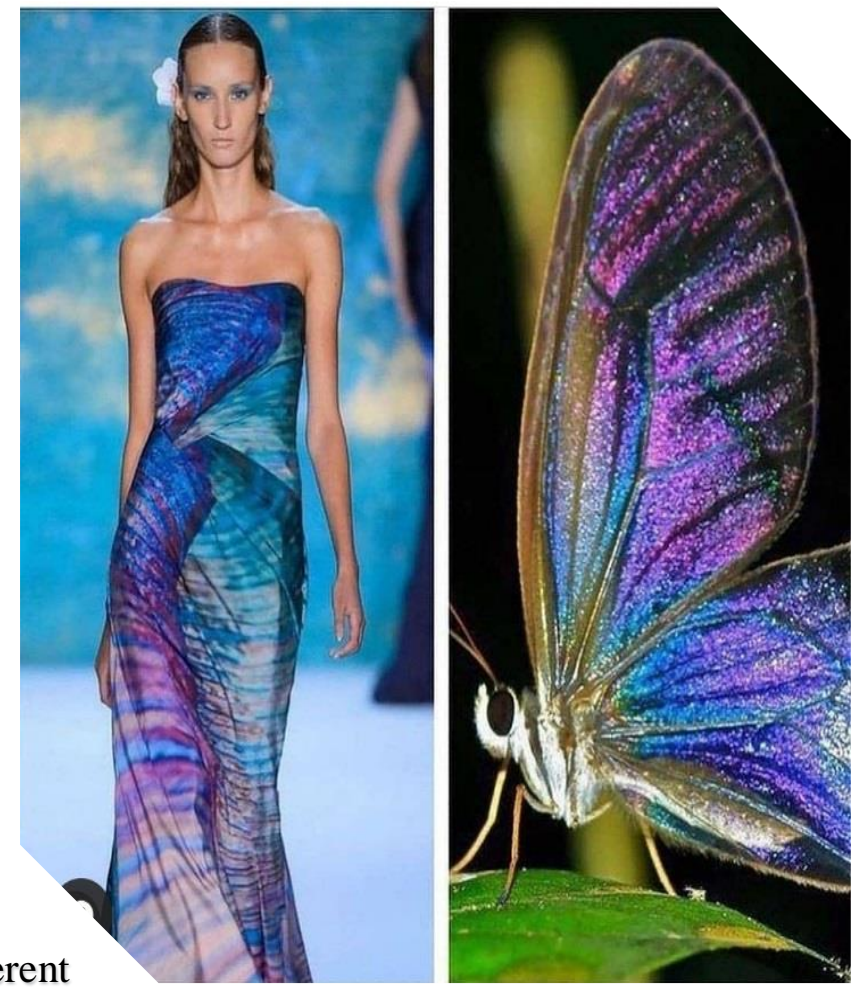

colours, or various fabrics in similar colours, to demonstrate his competence in the interplay between form, colour, and texture. James were able to generate incredible depth in his clothing by using the distinct tactile properties of various textiles and colours.

Butterfly" has a cream and brown colour scheme, yet the neutral tones don't detract from the dress's rich drama ("Butterfly," Art Museum). James also added unexpected splashes of colour by incorporating purple tulle within the billowing skirt fabric, which could be seen when the garment moved. 
The garment, which was made of silk chiffon, silk satin, and 25 yards of nylon tulle, encased the wearer's body in exquisite femininity and luxury. The gigantic bustle skirt, which weighed eighteen pounds and had satin side flanges that resembled butterfly wings, flowed quickly with the wearer's figure. Indeed, the gown's owner claimed to have purchased two opera seats, one for her skirt and the other for the burst of tulle, or "wings," of her butterfly dress (Coleman). In order to fulfil his goals, James used a variety of complicated and unique building methods. [4].
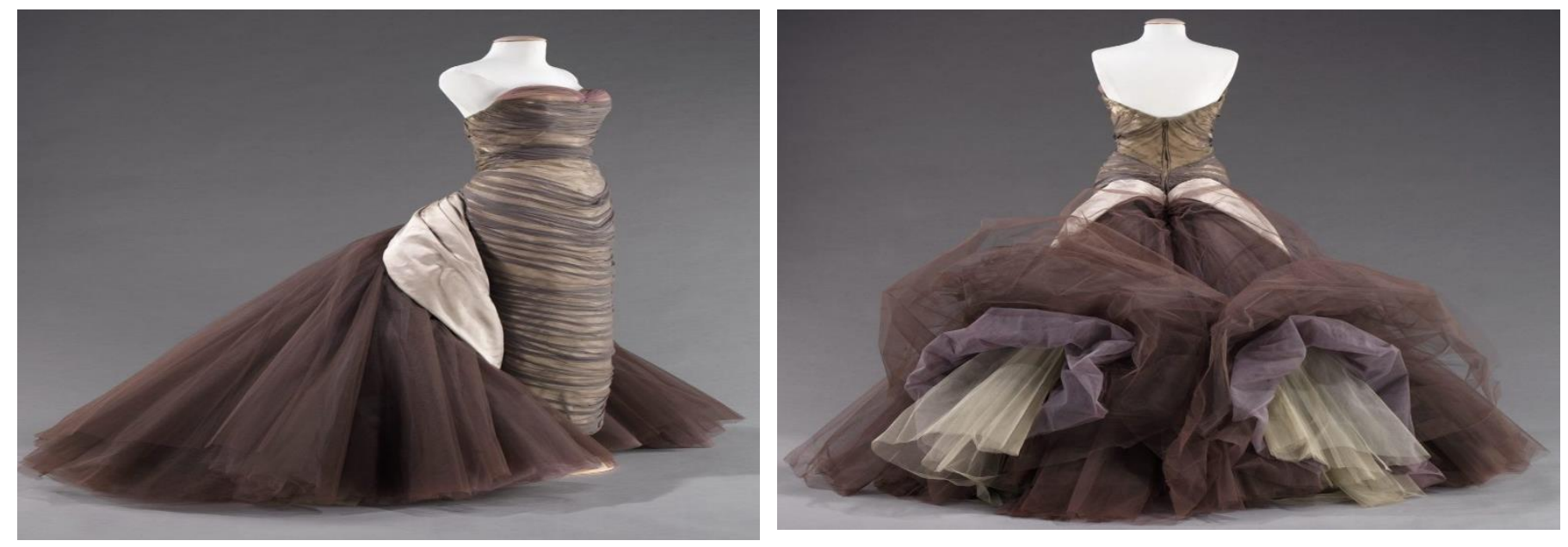

\subsubsection{Swarovski show:}

The Dubai-based designer a 20 -foot train that resembles "a butterfly emerging from its cocoon," the gown is made of Swarovski crystals and French pastels. Cinco estimates that it took 3,000 hours to complete the intricate work. (If the dressmakers worked nonstop, it would be 125 days.) Cinco designed the crystal-encrusted gown for a Swarovski show, but the actress collaborated with him to make it her own.

\subsubsection{Ashi Studio:}

In bright pink Ashi Studio couture, the Canes Film Festival journals look sensational. Ashi Studio's Summer/Spring 2018 Collection's origami gown on Zuhair Murad gown was worn by Deepika. 
She wore a Lorraine Schwartz diamond earring. After a vibrant purple suit and a shimmering gold gown, Deepika Padukone chose the hot pink piece for her second day in Cannes this year.
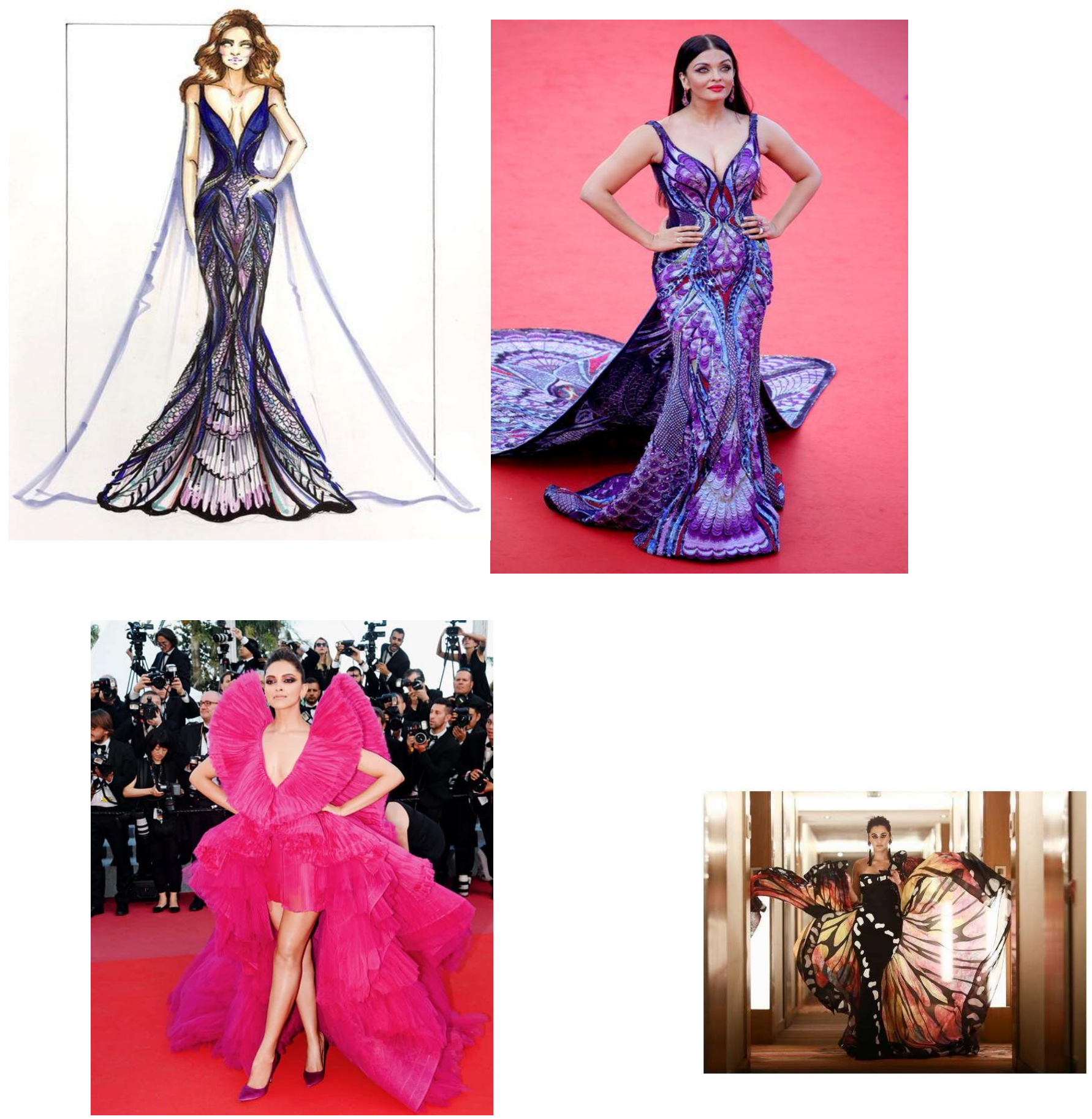


\section{Amazon film fare Award 2020:}

Tapsee Pannu was worn The butterfly effect in a Fouad Sarkis gown, voluminous sleeve, off shouldered goodness and butterfly-winged train, tasselled earrings from Azotiique perfectly accessorized her butterfly gown[5].

\section{Conclusion:}

There are many different ways that designers get their ideas for clothes, and this article explains what each one is like. Recognizes that various sources of inspiration aid in the creation of particular design components and concepts. In the early phases of fashion research and strategic collection planning, sources of inspiration have a strong influence in fostering uniqueness throughout the creative stage of the design process. Clothing design is a creative and innovative process that relies heavily on a wide range of sources of inspiration. Practical assistance is provided for both fashion designers and design-driven apparel businesses.

\section{References:}

1. Mengyuan Zheng -Application of Moire in Modern Dress, Advances in Social Science, Education and Humanities Research, volume 572 Proceedings of the 7th International Conference on Arts, Design and Contemporary Education (ICADCE 2021), Page No. 365 - 370.

2. Young Min lee, Young Hee Lee, Fashion Design Denim Inspired by Butterfly Motif Based the concept of Naturalism-Journal of Korean Society of Clothing \&Textiles, Vol 30 no.3, 2006- PP 412-424.

3.Dr.M. Sumithra Advanced Garment Construction Guide, Woodhead Publishing India Pvt. Ltd., PP.No. 119 121.

4. https://fashionhistory.fitnyc.edu/1955-charles-james-butterfly-dress-2/

5. https://www.republicworld.com/entertainment-news/bollywood-news/taapsee-pannu-literally-looked-likea-butterfly-in-this.html 